\title{
Primary infratentorial diffuse large b-cell lymphoma: a challenging diagnosis in an immunocompetent patient
}

\author{
(D) Gabriel Laverdi Beraldo ${ }^{1}$ \\ (DD) Angelo Borsarelli Carvalho Brito ${ }^{2}$ \\ (D) Márcia Torresan Delamain ${ }^{2}$ \\ (D) Carmino Antonio de Souza ${ }^{2}$ \\ (D) Carmen Silvia Passos Lima ${ }^{2}$ \\ (iD) João Felipe Leite Bonfitto ${ }^{3}$ \\ (iD) Luciano de Souza Queiroz ${ }^{3}$ \\ (iD) Fabiano Reis ${ }^{1}$
}

\begin{abstract}
1. Department of Radiology, Faculty of Medical Sciences, University of Campinas, Campinas, São Paulo, SP, Brasil 2. Department of Internal Medicine, Faculty of Medical Sciences, University of Campinas, Campinas, São Paulo, SP, Brasil 3. Department of Pathology, Faculty of Medical Sciences, University of Campinas, Campinas, São Paulo, SP, Brasil
\end{abstract}

\section{SUMMARY}

We describe the case of a female patient, 52 years old, with dizziness and left motor incoordination for 2 weeks. Brain MRI magnetic resonance imaging) revealed a hyperintense lesion on T2-weighted images, without restricted diffusion, in the left middle cerebellar peduncle. Spectroscopy demonstrated peak of lipids and perfusion did not show any elevation in relative cerebral blood volume ( $r C B V$ ). The patient underwent an open biopsy and resection, and the diagnosis of diffuse large B-cell lymphoma (DLBCL) was established. The patient received intravenous dexamethasone with symptoms remission, followed by four cycles of methotrexate plus cytarabine. After 3 months, the patient returned with decreased consciences level and a new MRI revealed a right superior frontal gyrus lesion with features suggesting a lymphomatous lesion. The patient died five days after her relapse.

KEYWORDS: Cerebellum. Lymphoma, Large B-Cell, Diffuse. Magnetic Resonance Spectroscopy. Middle cerebellar peduncle.

\section{INTRODUCTION}

Primary central nervous system lymphoma (PCNSL) is an unusual form of extranodal non-Hodgkin lymphoma that may affect the brain, leptomeninges, spinal cord or eyes, representing 3\% of all intracranial neoplasms ${ }^{1,2}$. It is less frequent in immunocompetent patients, and the average age of diagnosis in these patients is 50-65 years ${ }^{1,2}$. Regarding location, only $9 \%$ of PCNSL is found in the cerebellum, and it usually presents as a single lesion (60$70 \%)^{2-4}$. Microscopic features of the lesions show diffuse large B-cell lymphoma (DLBCL) in 90\% of the cases ${ }^{5}$. On neuroimaging, lymphomas tend to have an iso to low signal on T2-weighted images and restricted diffusion due to high cellularity. When these 
features are not observed, as in our case, infratentorial PCNSL may be a challenging diagnosis, and other differential diagnoses, such as metastatic tumors, malignant gliomas, demyelination and inflammatory disorders including neurosarcoidosis should be considered ${ }^{3,6}$. Herein we report a case of dizziness and ataxia, in which neuroimaging shows an expansive lesion in left middle cerebellar peduncle, with the final diagnosis of diffuse large B-cell lymphoma.

\section{CASE REPORT}

A 52-year-old Caucasian woman with no significant past medical history presented with symptoms of dizziness and left motor incoordination for 2 weeks at the Hematology and Hemotherapy Center of the University of Campinas. The initial physical and neurological examination revealed ataxic gait and dysdiadochokinesia. She underwent a brain computed tomography (CT) which revealed an expansile lesion of the posterior fossa. Brain magnetic resonance imaging (MRI) showed a heterogeneous lesion in the left middle cerebellar peduncle, with hyperintensity on
T2-weighted and intense enhancement on T1-weighted after contrast (Figures 1A and B). Spectroscopy showed a peak of lipids on $1.3 \mathrm{ppm}$, without choline elevation and perfusion did not demonstrate an elevation in rCBV (Figure 1C). She was seronegative for HIV 1 and 2, HBsAg and anti-HCV antibodies. The cerebrospinal fluid examination was unremarkable. No additional lesions were seen in a CT of the chest, abdomen, and pelvis, and the bone marrow biopsy showed no evidence of malignancy. The differential diagnoses included inflammatory demyelinating and infectious conditions versus lymphoproliferative malignancies, as the lesion had low perfusion and peak of lipid, features observed in both conditions.

The patient underwent an open biopsy of the tumor and resection; histological examination showed diffusely infiltrative large cells with scant cytoplasm, evident nucleoli, and frequent mitotic figures. Immunohistochemical profiling revealed a diffuse large B cell lymphoma, non-germinal center (Figure 2). Bone marrow involvement was negative. The diagnosis of stage IE (Ann Arbor staging system) DLBCL of the cerebellum was established.

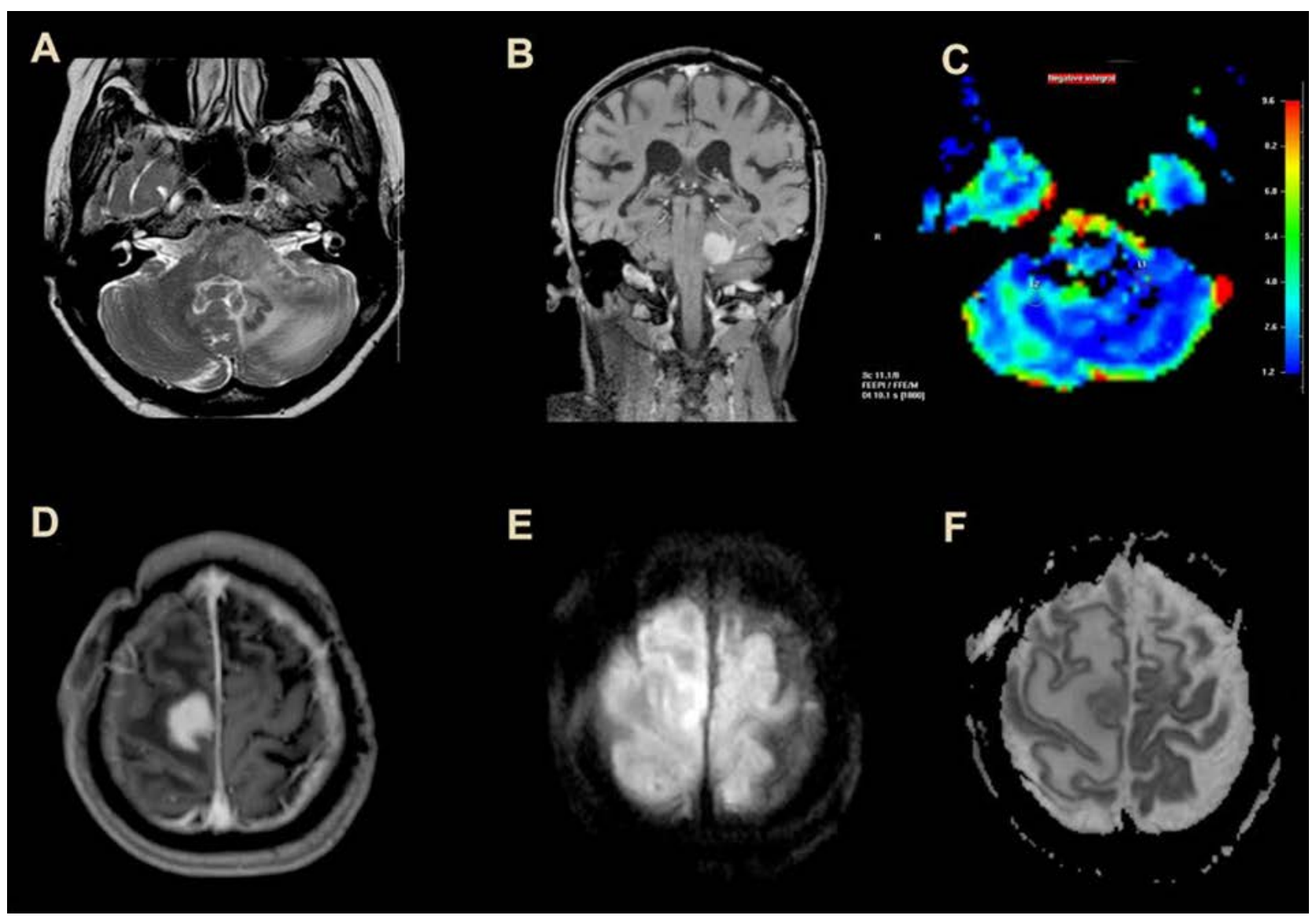

FIGURE 1 

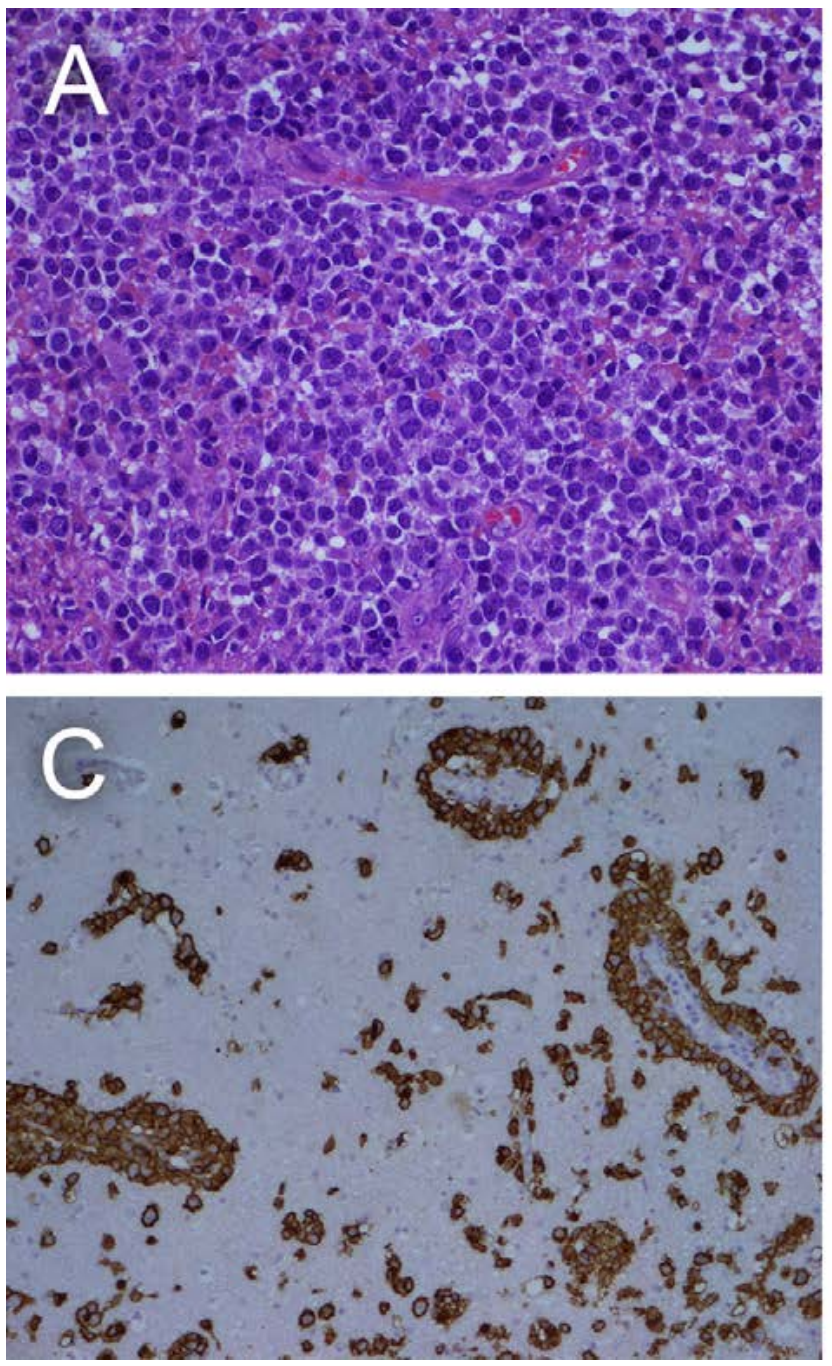

FIGURE 2

Intravenous dexamethasone was initiated, and the patient had symptoms remission. After that, the patient received four cycles of high-dose methotrexate and cytarabine (IELSG 20 Protocol) ${ }^{7}$. During the treatment, she experienced hematologic toxicity grade 3 and 4, febrile neutropenia and received antibiotic therapy. The patient had improvement after the fourth cycle of chemotherapy. MRI was used for control and presented complete remission of the initial tumor. Cranial radiotherapy was not performed. She remained with motor sequels, left hemiparesis and reduced muscle strength. After 3 months, she returned with decreased consciences level, sleepily, two episodes of seizures and difficulty in swallowing. A new MRI showed homogeneous nodular lesion in the right superior frontal gyrus (Figure 1D) with restricted diffusion (Figures 1E and F) and a peak of lipids on spectroscopy; the aspects were suggestive of lymphoma in the frontal convexity, but a new biopsy was not performed. The patient died after five days.
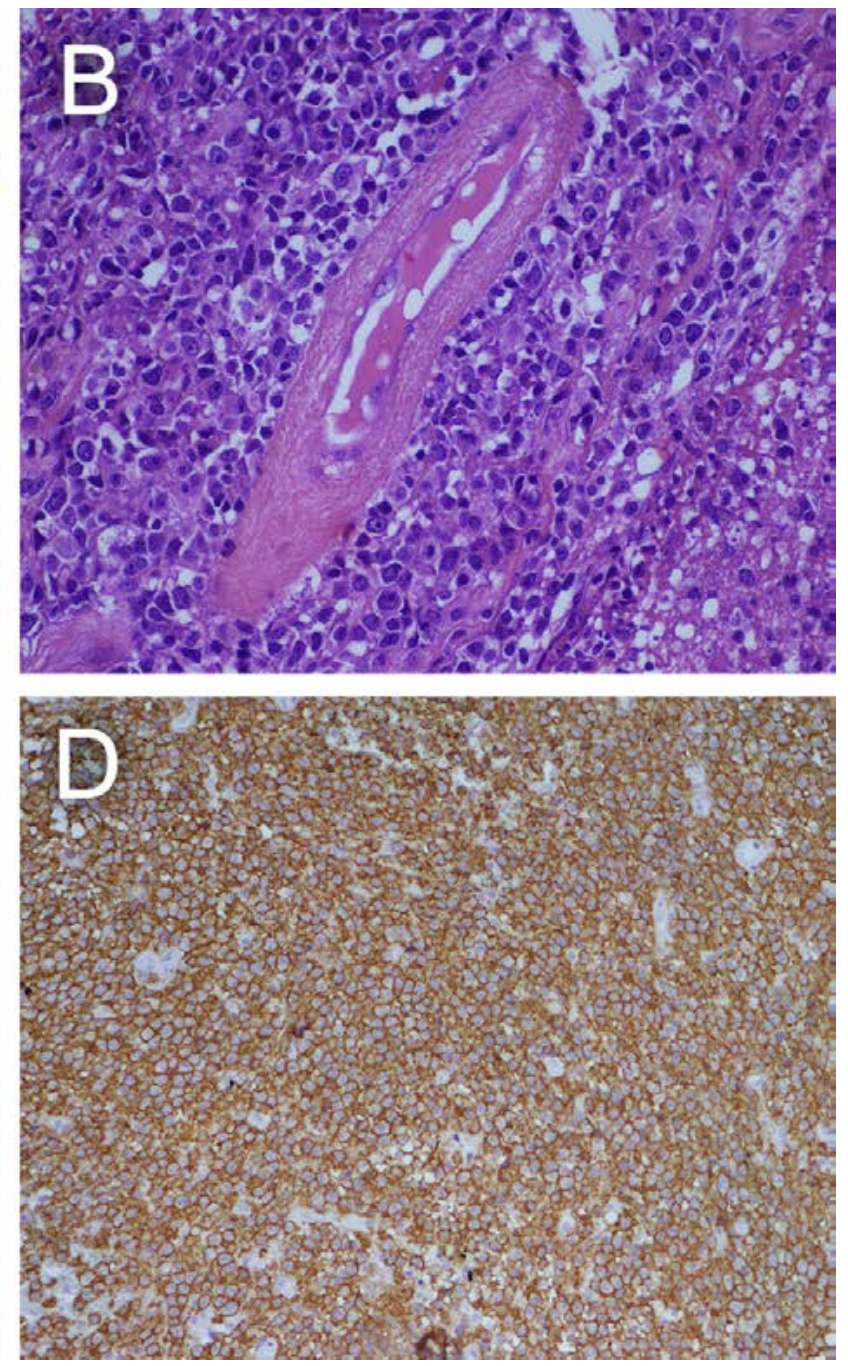

\section{DISCUSSION}

PCNSL is rare among intracranial neoplasms (only $3 \%$, with a yearly incidence of 0,5 case per 100.000 people ${ }^{2,3}$. Only a small proportion (13\%) is located in the infratentorial brain, of which $9 \%$ affect the cerebellum ${ }^{2,3,8}$, with the involvement of the middle cerebellar peduncle being even rarer. In immunocompetent patients, as the case described, the lymphoma mostly affects those in the fifth decade of life 9 .

The involvement of the cerebellum and other deep structures (periventricular regions, basal ganglia, and brainstem) is considered by some prognostic scores as independent image criteria associated with poor outcome and reduced survival ${ }^{10}$, which explains the importance of the site of the lesion.

As for neuroimaging, PCNSL typically presents as an iso to hypointense lesion on T2-weighted, in some cases with perilesional edema. Diffusion restriction is observed in the solid components of the lesion (due to high cellularity), and intense and homogeneous 
enhancement is frequently found ${ }^{3}$. Central necrosis is not usually found in immunocompetent patients, it is more common in immunocompromised ${ }^{6}$.

The pattern of central nervous system lymphomas on spectroscopy is similar to that of other highgrade tumors, and there is usually increased choline, reduced myoinositol and a peak of lipids and lactate in the solid portion on spectroscopy. In this case, there was no choline elevation, and only lipids were observed in the spectra.

Neuroimaging is very important to suggest, through certain characteristics as described, the nature of the injury. However, in some atypical cases as this, some differential diagnosis such as metastatic lesions, gliomas, and inflammatory processes, particularly granulomatous disease, should be considered.

In the case of our patient, the first MRI showed an infiltrative lesion in the left middle cerebellar peduncle, characterized by a heterogeneous signal on $\mathrm{T} 2$ and extension to adjacent cerebellar deep nuclei (Figure 1A and 1B). In the sequences of perfusion, hypoperfusion (low rCBV) was noted (Figure 1D), suggesting that the main differential diagnosis could be lymphoma, inflammatory and demyelinating processes (common etiology of middle cerebellar peduncle). Low perfusion in PCNSL is observed due to the low induction of neovascularization and destruction of the elements of the blood-brain barrier ${ }^{4}$.

Neurosarcoidosis, infectious granulomatous diseases (such as tuberculosis and paracoccidioidomy- cosis) and vasculitis should be considered in these lesions especially if it shows enhancement ${ }^{11}$. Granulomatous disease lesions can be of single/multiple iso or hypointense on T1-weighted and hypointense on T2-weighted, usually with low perfusion. Vasculitis and neurosarcoidosis usually involve younger patients, and infratentorial gliomas are more frequent in pediatric patients. Metastases can occur in this region and in this age group, usually iso or hyporintenseon T1-weighted and hyperintense on T2-weighted and FLAIR (hypointense if the primary neoplasm is from the gastrointestinal tract). However, they are hyperperfused on rCBV. Demyelination diseases are characterized by a hyperintense signal in T2-weighted and FLAIR, showing low perfusion when compared to lymphoma, and usually occurs in younger patients.

Due to the atypical MRI pattern suggesting an etiology, a biopsy was performed, and the diagnosis of DLBCL was established.

The patient underwent 4 cycles of high-dose methotrexate and cytarabine (IELSG 20 protocol) ${ }^{7}$ and obtained complete remission, as previously reported. She was not submitted to cranial radiotherapy. Later, another lesion with typical lymphoma features was diagnosed in the supratentorial brain.

Infratentorial DLBCL is a rare entity, and may also be misdiagnosed in immunocompetent patients, in the context of atypical MRI lesions.

The prognosis is poor, and there is scarce knowledge about its cause and optimal clinical management.

\section{RESUMO}

Descrevemos o caso de uma paciente do sexo feminino, de 52 anos, apresentando história de tontura e perda da coordenação motora do lado esquerdo há duas semanas. A RM (ressonância magnética) de crânio revelou uma lesão hiperintensa nas imagens ponderadas em T2, sem restrição à difusão, localizada no pedúnculo cerebelar médio esquerdo. A espectroscopia demonstrou pico de lipídeos, sem elevação do volume sanguíneo cerebral relativo ( $r C B V$ ) à perfusão. A paciente foi submetida à biópsia a céu aberto, estabelecendo o diagnóstico de linfoma difuso de grandes células $B(D L B C L)$. Houve remissão dos sintomas após o início do tratamento com dexametasona endovenosa, seguida de quatro ciclos de metotrexato associado à citarabina. Após três meses, a paciente retornou apresentando rebaixamento do nível de consciência, e a RM de crânio revelou uma nova lesão de origem linfomatosa no giro frontal superior direito. A paciente faleceu após cinco dias.

PALAVRAS-CHAVE: Cerebelo. Linfoma difuso de grandes células B. Espectroscopia de ressonância magnética. Pedúnculo cerebelar médio.

\section{REFERENCES}

1. Makhdoomi R, Nayil K, Rayees A, Kirmani A, Ramzan A, Khalil MB, et al. Primary CNS lymphoma in immunocompetent: a review of literature and our experience from Kashmir. Turk Neurosurg. 2011;21(1):39-47.

2. Datta A, Gupta A, Choudhury KB, Dhyani A, Majumdar A. Primary cerebellar B cell lymphoma: a case report. Int J Case Rep Imag. 2013;4(9):498-501.

3. Küker W, Nägele T, Korfel A, Heckl S, Thiel E, Bamberg M, et al. Primary central nervous system lymphomas (PCNSL): MRI features at presentation in 100 patients. J Neurooncol. 2005;72(2):169-77.
4. Partovi S, Karimi S, Lyo JK, Esmaeili A, Tan J, Deangelis LM. Multimodality imaging of primary CNS lymphoma in immunocompetent patients. $\mathrm{Br}$ J Radiol. 2014;87(1036):20130684.

5. Commins DL. Pathology of primary central nervous system lymphoma. Neurosurg Focus. 2006;21(5):E2.

6. Lanfermann H, Heindel W, Schaper J, Schröder R, Hansmann ML, Lehrke $\mathrm{R}$, et al. CT and MR imaging in primary cerebral non-Hodgkin's lymphoma. Acta Radiol. 1997;38(2):259-67. 
7. Ferreri AJ, Reni M, Pasini F, Calderoni A, Tirelli U, Pivnik A, et al. A multicenter study of treatment of primary CNS lymphoma. Neurology. 2002;58(10):1513-20.

8. Cellina M, Fetoni V, Baron P, Orsi M, Oliva G. Unusual primary central nervous system lymphoma location involving the fourth ventricle and hypothalamus. Neuroradiol J. 2015;28(2):120-5.

9. Chen D, Gu W, Li W, Liu X, Yang X. Primary diffuse large B-cell lymphoma of the central nervous system: a case report and literature review. Oncol Lett. 2016;11(5):3085-90.

10. Ferreri AJ, Blay JY, Reni M, Pasini F, Spina M, Ambrosetti A, et al. Prognostic scoring system for primary CNS lymphomas: the International Extranodal Lymphoma Study Group experience. J Clin Oncol. 2003;21(2):266-72.

11. Morales $\mathrm{H}$, Tomsick T. Middle cerebellar peduncles: magnetic resonance imaging and pathophysiologic correlate. World J Radiol. 2015;7(12):438-47. 